\title{
Mechanistic insight into softening of Canadian wonder common beans (Phaseolus
} vulgaris) during cooking

Claire Maria Chigwedere ${ }^{a^{*}}$, Taye Foyeke Olaoye ${ }^{a}$, Clare Kyomugasho ${ }^{a}$, Zahra Jamsazzadeh Kermani ${ }^{\mathrm{a}}$, Andrea Pallares Pallares ${ }^{\mathrm{a}}$, Ann M. Van Loey ${ }^{\mathrm{a}}$, Tara Grauwet ${ }^{\mathrm{a}}$, and Marc E. Hendrickx ${ }^{a}$.

\section{Corresponding author: marceg.hendrickx@kuleuven.be}

\section{*Tel.: +32 16321572}

\section{aLaboratory of Food Technology, Leuven Food Science and Nutrition Research Center} (LFoRCe), Department of Microbial and Molecular Systems (M²S), KU Leuven, Kasteelpark Arenberg 22 Box 2457, 3001, Heverlee, Belgium.

\section{Chemical compounds in the article}

1. Aluminum oxide_PubChem CID 9989226

2. 1-Butanol_PubChem CID 263

3. Indium_PubChem CID 5359967

4. Sodium bicarbonate_PubChem CID 516892

\section{Abstract}

The relative contributions of cotyledons and seed coats towards hardening of common beans (Phaseolus vulgaris) were investigated and the rate-limiting process which controls bean softening during cooking was determined. Fresh or aged whole beans and cotyledons were soaked and cooked in demineralised water or $0.1 \mathrm{M} \mathrm{NaHCO}_{3}$ solution, and texture evolution, microstructure changes and thermal properties were studied. Fresh and aged whole beans cooked in demineralised water had significantly different softening rate constants and so did fresh and aged cotyledons. The comparable softening rate constants of aged whole beans and cotyledons indicated an insignificant role of the seed coat in hardening during storage. All samples cooked faster in $0.1 \mathrm{M} \mathrm{NaHCO}_{3}$ solution. Disintegration of cooked tissues followed by microscopic examination revealed a transition from cell breakage through a phase of cell breakage and separation to complete cell separation with increased cooking time wherefore texture decayed. Therefore, progressive solubilisation of pectin in the middle lamella greatly promoted texture decay. While residual birefringence even after substantial cooking time suggested some order of the starch, calorimetric analyses revealed complete starch gelatinisation before complete cell separation occurred. This implies an insignificant role of starch in texture decay during cooking but its hindered uncoiling into a viscous gel after gelatinisation due to the restricting cell wall could promote its retrogradation. Therefore, 
we suggest that the rate-determining process in bean softening relates to cell wall/middle lamella changes influencing pectin solubilisation.

\section{Keywords}

Bean cotyledons; Bean seed coats; Starch gelatinisation; Cell separation; Pectin solubilisation; Texture evolution

\section{Introduction}

Common beans ( $P$. vulgaris) are nutrient-rich legumes consisting of proteins, complex carbohydrates, vitamins and micronutrients such as iron and zinc (Berrios et al., 1999). Besides being an alternative source of protein to animal sources, beans are characterized by a low glycemic index owing to high quantities of resistant starch, bonding of starch to phosphate groups of phytic acid making it less available for digestion, and formation of a viscous gel-like solution in the stomach which moves slowly to the small intestines thus delaying absorption of glucose into the blood stream (Cuvelier et al., 2017). Next to these nutrition and health-related factors, beans are affordable and their production is sustainable, hence they are increasingly becoming of great interest to food technologists and nutritionists. Nonetheless, the utilization of beans is greatly challenged by the development of the hard-tocook (HTC) defect, a phenomenon that develops during storage under uncontrolled temperature and relative humidity conditions. As a result, beans require a longer cooking time to attain desirable texture, a crucial quality attribute for consumer acceptability (StolleSmits et al., 1997).

According to Waldron et al. (2003) and Sila et al. (2005), texture greatly depends on mechanical properties of the cell wall that enclose cells and the middle lamella that cements cells together to form tissues. Therefore, it is not surprising that the most plausible hypotheses of HTC development, being the pectin-cation-phytate and lignification mechanisms involve these layers. In the former hypothesis, it is suggested that enzymatic hydrolysis of phytate results in the release of divalent cations which crosslink demethylesterified pectin polymers in the middle lamella thereby forming thermostable pectates that retard tissue softening during cooking (Paredes-López et al., 1991). In the lignification hypothesis, free polyphenols, aromatic amino acids released by enzymatic degradation of proteins and soluble tannins suggested to migrate from the seed coats to cotyledons contribute to lignin deposition in cotyledon cell walls and middle lamellae, leading to long cooking times (Hincks and Stanley, 1986; Hohlberg and Stanley, 1987; Stanley, 1992). Other mechanisms suggested to play a role in HTC development, though less plausible, include structural changes in starch and, oxidation and polymerization of lipids (EI- 
Tabey Shehata, 1992). Efforts to elucidate mechanisms of HTC development revealed that both cotyledons and seed coats contribute to HTC development but evidence of the extent of their individual contributions is still lacking.

To prevent HTC or render beans less prone to its development, storage of beans under controlled conditions of temperature and relative humidity has been proposed (ReyesMoreno et al., 2000). Different methods to reduce the severity of HTC in bean processing have been reported and the most commonly applied is soaking, during which the beans are hydrated to facilitate cooking (Hincks and Stanley, 1986). Moreover, soaking and cooking of beans in solutions of high $\mathrm{pH}$, monovalent cations and chelating agents rather than demineralised water was reported to reduce cooking time of beans (Hincks and Stanley, 1986; del Valle and Stanley, 1995; Pirhayati et al., 2011; Kinyanjui et al., 2015). Monovalent cations are believed to displace divalent cations that are suggested to inherently crosslink pectin polymers (as described in the pectin-cation-phytate hypothesis), whilst chelating agents bind them. This renders the once thermostable pectates thermolabile, thus faster cooking. However, textural changes during thermal processing of starchy foods such as cassava roots (Manihot esculenta), potatoes (Solanum tuberosum) and sweet potatoes (Ipomoea batatas) involve hydration, gelatinisation and solubilisation of starch in addition to solubilisation of cell wall and middle lamella polymers (Binner et al., 2000; Menoli and Beleia, 2007). Mechanistic insights into the hydration of common beans during soaking and cooking were investigated by Swanson et al. (1985), Kikuchi et al. (2006), Piergiovanni (2011), Zhang and McCarthy (2013), and Mikac et al. (2015). However, mechanistic insights of bean softening in the context of the process which controls the softening of beans during cooking, either starch gelatinisation or solubilisation of polymers in the cell wall and middle lamella, is lacking in literature. This is interesting given that common beans contain a high starch content (22-45\% on dry matter basis) (Hoover et al., 2010).

The current study was therefore aimed at investigating the relative contributions of seed coats and cotyledons to HTC development in common beans as well as the extent to which polymer (starch and polymers in the cell wall and middle lamella) solubilisation during cooking govern the texture decay of beans. Particularly, fresh beans (with and without seed coats) and beans hardened with and without seed coats were assessed for the extent of hardening through a cooking experiment followed by texture analysis. Subsequently, the samples were disintegrated and examined microscopically and/or calorimetrically for the dynamics of the associated tissue failure mechanisms and starch gelatinisation. It was the intention of this study to direct the focus of any subsequent studies involving elucidation of HTC and/or cooking behavior on the macro structural component of significance for HTC 
development and/or the rate limiting process that governs cooking behavior of beans, respectively.

\section{Materials and methods}

\subsection{Raw materials}

Canadian wonder common beans (Phaseolus vulgaris) grown, harvested and solar dried at Thika Station (Kenya Agricultural and Livestock Research Organization, Kenya) were used. First, the beans were cleaned and sorted to remove dirt and defective beans, respectively. A part of the beans was kept as whole beans while the rest was manually peeled using a hand knife, to separate seed coats from cotyledons. Whole beans and cotyledons were then either aged by storing them at $35^{\circ} \mathrm{C}$ and $83 \%$ relative humidity (achieved using saturated potassium chloride solution) for three months (herein referred to as aged whole beans or cotyledons) or not aged (referred to as fresh whole beans or cotyledons). This was aimed at facilitating investigation of the relative contributions of cotyledons and seed coats to HTC development. All the aforementioned materials were stored in a freezer at $-40{ }^{\circ} \mathrm{C}$ until use. $\mathrm{A}$ schematic illustration of the experimental approach for this study is shown in Figure 1.

\subsection{Thermal treatment-induced texture evolution of bean materials}

In order to assess the extent of development of HTC, cooking profiles of fresh and aged whole beans/cotyledons soaked and subsequently cooked in either demineralised water or sodium bicarbonate $\left(\mathrm{NaHCO}_{3}\right)$ solution were determined. The latter medium facilitated assessment of the influence of $\mathrm{pH}$ and monovalent cations on texture evolution. Cooking profiles were generated by measuring hardness of cooked fresh and aged cotyledons as well as cotyledons obtained from cooked fresh and aged whole beans as a function of cooking time.

\subsubsection{Soaking and cooking of bean materials}

First, fresh and aged whole beans/cotyledons were each soaked in either media in a ratio of $1: 5(\mathrm{w} / \mathrm{v})$ at $25^{\circ} \mathrm{C}$ for $16 \mathrm{~h}$. Thereafter, exactly 20 seeds were drawn to serve as the control sample, herein referred to as cooked for $0 \mathrm{~min}$. The rest of the soaked seeds were cooked at $95{ }^{\circ} \mathrm{C}$, with sampling of 20 seeds at different intervals depending on the cooking medium $(0.1$ $\mathrm{M} \mathrm{NaHCO}_{3}$ solution or demineralised water), type of material (whole beans or cotyledons) and condition of material (fresh or aged). Fresh and aged whole beans as well as aged cotyledons cooked in water were sampled every $30 \mathrm{~min}$ whilst fresh cotyledons were sampled every $15 \mathrm{~min}$. In contrast, fresh and aged whole beans cooked in $0.1 \mathrm{M} \mathrm{NaHCO}_{3}$ solution were sampled every 15 min whilst fresh and aged cotyledons were sampled every $10 \mathrm{~min}$. 


\subsubsection{Measurement of hardness}

Measurement of hardness as an indicator of texture was done on a single cotyledon per seed, thus, whole beans were peeled after sampling. Therefore, the experimental design involved repeated sampling at each moment of treatment. A TA-X2i texture analyzer (Stable Microsystems, Goldaming, England) equipped with a $25 \mathrm{~kg}$ force cell and a cylindrical flat head aluminum probe of diameter $25 \mathrm{~mm}$ was utilized. The pre-test, test and post-test speeds of the probe were 2, 1 and $2 \mathrm{~mm} / \mathrm{s}$, respectively. A single cotyledon from each of 20 sampled seeds was then placed onto the lower plate of the texture analyzer, the probe was lowered and hardness measured as the maximum gram-force $(\mathrm{g})$ required to compress a cotyledon to $75 \%$ strain. Per cooking time, material and medium, the average hardness of the 20 measurements and its associated standard deviation were calculated. The data obtained were normalized by dividing the hardness at a given cooking time $t(H)$ by that of the control $\left(\mathrm{H}_{0}\right.$, hardness at 0 min cooking time). A plot of normalised hardness against cooking time revealed the texture evolution of the materials.

\subsection{Visualization of the dynamics of microstructure during thermal treatment}

Next to investigating texture evolution, it was of interest to examine microstructure changes in order to determine the mode(s) of tissue failure upon disintegration of the cooked materials as well as to qualitatively establish the extent of starch gelatinisation during cooking. This approach was aimed at revealing the mechanism(s) governing softening of beans during cooking. Per cooking time and medium, the sample (cotyledons used for hardness measurement and those that were not) was disintegrated to paste consistency using mortar and pestle. An aliquot of the paste was used to make a suspension in demineralised water for preparation of a microscopic slide. An Olympus BX-41 microscope (Olympus, Optical Co. Ltd., Tokyo, Japan) equipped with differential scanning contrast (DIC) mode and polarized light mode was utilized for microstructure examination and micrographs were captured using Cell Image analysis software (Soft Imaging System, Munster, Germany). For each view under DIC mode, a corresponding one under polarized light was performed for qualitative assessment of the extent of starch gelatinisation.

\subsection{Thermal analysis using differential scanning calorimetry}

Following microstructure examination, the bean materials were lyophilized (using a Christ Alpha Plus 2-4 lyophilized Osterode, Germany) and dry matter content was established through moisture content determined using the oven-drying method. Moisture content was determined in duplicate as weight loss from $2 \mathrm{~g}$ of sample after oven drying at $103^{\circ} \mathrm{C}$ for 20 h. Thermal analysis was then performed for quantitative measurement of enthalpy and transition temperatures of thermal events in the bean materials with main focus on starch. $A$ 
V24.11 Build 124 Q2000 heat flux differential scanning calorimeter (DSC) designed with Advanced Tzero ${ }^{\mathrm{TM}}$ technology (TA Instruments, Delaware, United States of America) and equipped with a refrigerated cooling system (RCS 90) was utilized. Cell constant and temperature calibrations and verifications were performed under T4 heat flow using indium as recommended by the manufacturer. The DSC cell was purged with $\alpha-2$ nitrogen gas at 50 $\mathrm{mL} / \mathrm{min}$. Flattened indium of known weight was encapsulated in a high volume stainless steel pan atop a weighed thin layer of aluminum oxide using a Tzero press and die set (TA Instruments, Delaware, United States of America). A similar pan containing a layer of aluminum oxide only was used as a reference pan. Approximately $10 \mathrm{mg}$ of sample was weighed into a similar pan and demineralised water $(1: 3 \mathrm{w} / \mathrm{v})$ was added. The pan was then sealed and the contents equilibrated at $20^{\circ} \mathrm{C}$ for $16 \mathrm{~h}$ in the autosampler of the DSC. Analysis was initiated by a 2 min equilibration of the sample at $20^{\circ} \mathrm{C}$ followed by a temperature ramp to $120^{\circ} \mathrm{C}$ at $5^{\circ} \mathrm{C} / \mathrm{min}$ with a sampling interval of $0.10 \mathrm{~s} /$ point. Analyses were done in duplicate and Version 4.5A Build 4.5.0.5 of Universal Analysis 2000 software (TA Instruments-Waters LLC) was used to analyze the obtained thermograms.

Since beans contain proteins and lipids which can exhibit thermal events due to denaturation and formation of amylose-lipid complexes, respectively, an attempt to identify these thermal events was made. First, water-extractable proteins (albumins) were extracted from cotyledon powders (of fresh and aged beans) lacking cellular structure after disintegration. Samples were mixed with demineralised water in a ratio of 1:20 (w/v) using end-over-end rotation at 4 ${ }^{\circ} \mathrm{C}$ for $5 \mathrm{~h}$ followed by centrifugation (Beckman model JS-HS, American Instrument Exchange, Inc.) at $20000 \mathrm{~g}$ and $4{ }^{\circ} \mathrm{C}$ for $30 \mathrm{~min}$. The obtained pellets were washed using the same volume of demineralised water as was used for extraction and then centrifuged as described above followed by lyophilisation of the pellets. Lipids were extracted from cotyledon powders (of fresh and aged beans) having or lacking intact cells after disintegration using water-saturated 1-butanol in a 1:10 (w/v) ratio with end-over-end rotation at $20^{\circ} \mathrm{C}$ for $1 \mathrm{~h}$ followed by centrifugation at $3000 \mathrm{~g}$ and $20^{\circ} \mathrm{C}$ for $5 \mathrm{~min}$. The extraction was repeated after which obtained pellets were air-dried overnight. Thermal analysis was conducted in duplicate as described above on samples from which albumin and lipids were extracted.

\subsection{Evaluation of the influence of the cell wall on thermal properties}

To explore the influence of the cell wall on thermal transitions in the bean materials, cell wall disruption was promoted through cryogenic milling. Cotyledons from fresh and aged whole bean materials (cooked in demineralised water) yielding only intact cells upon disintegration were either maintained with intact cells or cryogenically milled to disrupt the cell wall and 
release cell contents. For cryogenic milling, approximately $0.5 \mathrm{~g}$ of lyophilized (from material utilized under section 2.4) sample was weighed into a screw top stainless steel grinding jar containing 50 matching milling balls of diameter $5 \mathrm{~mm}$ each. The grinding jar was fastened into the cryomill (Retsch, Germany) and in a precooling step, the sample was embrittled at $-196{ }^{\circ} \mathrm{C}$ and $5 \mathrm{~Hz}$ for 3 min utilizing an integrated liquid nitrogen cooling system. Size reduction was achieved through impact and friction during a single cycle ball milling step at $-196{ }^{\circ} \mathrm{C}$ and $30 \mathrm{~Hz}$ with optimization of milling time to ensure total destruction of cell walls with minimum damage to the embrittled starch granules. Optimization of the cryogenic milling was assessed through microscopic examinations under DIC for destruction of cell walls. Following this, milled samples were subjected to thermal analysis as described under Section 2.4 .

\subsection{Data modeling and statistical analysis}

220 In order to compare the rate of change of hardness of the different materials in different media during investigation of thermal treatment-induced texture evolution in beans, the experimental data was modeled first by first order kinetics. Since the data were normalised, the model was expected to predict $\mathrm{H}_{0}$ as 1 but higher values were predicted for some curves due to their visible lag moments. Therefore, an empirical first order kinetic equation shown below was applied, using the SAS Proc Model procedure (SAS version 9.3, SAS Institute, Inc., Cary, NC, USA) even though there was only little improvement in some of the correlation coefficients.

$$
H=H_{0} \exp (-k(t-\Delta t))
$$

Where, $\mathrm{H}_{0}$ and $\mathrm{H}$ are hardness values at 0 min and $\mathrm{t}$ min cooking time, respectively, $\Delta \mathrm{t}$ is a time interval for which $\mathrm{H}=\mathrm{H}_{0}$ and $\mathrm{k}$ is the reaction rate constant (the rate of softening of bean material during thermal treatment) determined after $\Delta t$ min. From the obtained analysis of variance (ANOVA) table, the $\mathrm{R}^{2}$ adjusted was calculated in order to evaluate the fit of the model to the data and the root mean square error (RMSE) was calculated to determine the spread of the residuals. Statistical differences between $\mathrm{k}$ values of the different bean materials were determined using their confidence intervals. Data from thermograms obtained during thermal analysis was statistically analyzed using one way ANOVA and the student's t-test for pairwise comparison of means at $5 \%$ significance level using JMP Pro 13.1 .0 software (SAS Institute, Inc., 2016). 


\subsection{Texture evolution during cooking}

241

242

243

244

245

246

247

248

Given that cookability is the classic indicator of the extent of HTC development in legumes, this parameter was employed to assess the contribution of cotyledons and seed coats of beans to HTC development. Cooking profiles highlighting texture evolution of the different bean materials with cooking time are shown in Figure 2, wherein hardness of all materials decreased with increased cooking time irrespective of the cooking medium. However, from non-normalised hardness data (not shown), aged whole beans were harder than fresh whole beans after soaking in demineralised water (20151 \pm 2159 vs $15678 \pm 2774$, respectively) and in $0.1 \mathrm{M} \mathrm{NaHCO}_{3}$ solution (18745 \pm 3197 vs $15164 \pm 2123$, respectively) but this was not the case for cotyledons which had similar hardness after soaking in either media. Values of $\Delta t$ (time for which initial hardness is maintained $\left.\left(\mathrm{H}_{\mathrm{H}} \mathrm{H}_{0}\right)\right)$ and rate of softening $(\mathrm{k})$ estimated from an empirical first order kinetic model are shown in Table 1. From Figure 2, the profiles of fresh whole beans and fresh cotyledons cooked in demineralised water are comparable but their $k$ values (Table 1 ) are significantly different with the fresh cotyledons exhibiting a faster softening rate and texture decay. As such, the seed coat has a role in controlling cookability of beans possibly by slowing the rate of water imbibition during cooking. Kinyanjui et al. (2015) and Downie et al. (1997) reported similar results. Moreover, Jackson and Varriano-Marston (1981) affirmed seed coats to be the major hindrance to bean cookability, accounting for $60 \%$ of the cooking time of fresh black ( $P$. vulgaris) beans. In the current study, for aged materials, upon cooking of aged whole beans in demineralised water, the cooking curve shifted to the right (Figure 2) and the $\mathrm{k}$ value significantly decreased with respect to fresh whole beans cooked in the same medium. This is an indication of a slower softening rate and hence longer cooking time. A similar trend was observed for aged cotyledons which cooked at a slower rate compared to fresh cotyledons. The magnitude of differences between k-values were not considered due to differences in values of $\Delta$ t. Longer cooking times upon aging of whole beans were also observed by Njoroge et al. (2016), Wu et al. (2015), dos Santos Siqueira et al. (2013) and Machado et al. (2008) who attributed their observations to a series of proposed biochemical modifications which supposedly strengthen cell-cell adhesion in the beans during aging. These include pectate formation (ParedesLópez et al., 1991), lignin deposition (Hincks and Stanley, 1987; Martin-Cabrejas et al., 1997) and acidification of tissues leading to protein insolubilisation and reverse denaturation (Liu et al., 1992). In the current study, it can further be observed that the cooking curves of aged whole beans and aged cotyledons were nearly superimposable, with comparable (not significantly different) $\mathrm{k}$ values. Therefore, cotyledons developed HTC to the same extent as whole beans under the same storage conditions. Although Stanley (1992) reported migration 
of tannins from seed coats to cotyledons and suggested their condensation as a contribution to hardening, results from the current study reveal that this contribution is insignificant compared to that of cotyledons.

Examining the profiles of materials cooked in $0.1 \mathrm{M} \mathrm{NaHCO}_{3}$ solution, irrespective of the type (whole beans or cotyledons) and condition (fresh or aged) of the material, all cooking curves were shifted to the left with respect to those obtained for materials cooked in demineralised water (Figure 2). The former cooking curves exhibited much steeper slopes, an indication of faster cooking rates as evidenced by higher $\mathrm{k}$ values (Table 1 ). This can be explained by mainly the high $\mathrm{pH}$ of the $0.1 \mathrm{M} \mathrm{NaHCO}_{3}$ solution ( 8.3) and the presence of sodium $\left(\mathrm{Na}^{+}\right)$ ions. A positive influence of solutions of high $\mathrm{pH}$ and/or monovalent cations such as $\mathrm{NaHCO}_{3}$ and $\mathrm{Na}_{2} \mathrm{CO}_{3}$ on cookability of beans was also observed by (Njoroge et al., 2016) and Schoeninger et al. (2014). The high pH enhances solubilisation of polymers and hence the cooking rate of the beans (Kinyanjui et al., 2015). It is believed that $\mathrm{Na}^{+}$ions displace divalent cations such as calcium $\left(\mathrm{Ca}^{2+}\right)$ and magnesium $\left(\mathrm{Mg}^{2+}\right)$ inherently crosslinking pectin polymers in the middle lamella thus destabilizing the pectate structures and enhancing cookability (Varriano-Marston and Omana, 1979). In the current study, fresh whole beans cooked faster than aged whole beans but slower than fresh cotyledons in $0.1 \mathrm{M} \mathrm{NaHCO}_{3}$ solution as was also observed when the same materials were cooked in demineralised water. Interestingly, fresh and aged cotyledons which had significantly different softening behavior in demineralised water had similar softening behavior in $0.1 \mathrm{M} \mathrm{NaHCO}_{3}$ solution, indicating the efficacy of mainly the high $\mathrm{pH}$ of this solution and also presence of $\mathrm{Na}^{+}$ions in overcoming the HTC defect. Surprisingly, aged whole beans and aged cotyledons which had similar cooking behavior in demineralised water exhibited significantly different softening behavior in $0.1 \mathrm{M} \mathrm{NaHCO}_{3}$ solution. This suggests the role of the seed coat as a barrier to $\mathrm{pH}$ adaptation and/or migration of $\mathrm{Na}^{+}$ions from the cooking solution to the cotyledons, in addition to the earlier suggested role of retarding hydration during cooking.

\subsection{Microstructure changes during thermal treatment}

Cotyledons from fresh and aged whole beans (cooked in different media and for different times) were disintegrated using mortar and pestle in order to explore the qualitative changes in microstructure, that is, to establish the mode(s) of failure of cooked tissue upon disintegration as well as the extent of starch gelatinisation. In this section, only results of cotyledons of whole (fresh and aged) cooked beans are shown given that similar trends were observed for fresh and aged cotyledons cooked in either media. Micrographs of disintegrated cotyledons of fresh whole beans cooked in demineralised water are presented in Figure 3. For soaked ( 0 min cooking time) fresh whole beans (Figure $3 \mathrm{~A}$ ), free starch granules and cell 
wall material (shown by black and white arrows, respectively) were observed upon tissue disintegration. After 30 min of cooking, free starch granules along with separated intact cells (shown by black and white arrows, respectively) were observed while further cooking to 60 min and beyond yielded no free starch granules but only intact cells. Therefore, micrographs of samples cooked for longer than 60 min but less than $210 \mathrm{~min}$ are not shown. These observations can be explained by variations in failure mechanisms upon mechanical disintegration of plant tissues. Within plant tissues, cell constituents are surrounded by a cell wall, forming cells which are glued together by the middle lamella, a pectin-rich layer. During processing, modification of pectin in the middle lamella and the cell wall can occur, thereby compromising the integrity and consequently strength of these layers. The extent of modification dictates the mode of failure upon exertion of a force. When the middle lamella is weaker than the cell wall, exertion of a force leads to cell separation while a stronger middle lamella results in cell breakage.

In this context, at 0 min cooking time, the free starch granules and remnants of cell wall material observed for cotyledons of fresh whole beans are an indication that the middle lamella was stronger than the cell wall such that upon tissue disintegration, cell breakage occurred with release of the cell contents. This is in agreement with findings from Brummer et al. (2015) and Berg et al. (2012). Upon cooking for $30 \mathrm{~min}$, in the current study, onset of heat-induced polymer solubilisation, especially of pectin, probably initiated weakening of the middle lamella such that during disintegration, some cells were separated whilst others were broken (releasing the free starch granules observed). Simultaneous occurrence of cell breakage and separation indicates non-uniformity of pectin modification in the middle lamella. Upon prolonged cooking of fresh whole beans (60 min and beyond), progressive pectin modification probably further weakened the middle lamella, such that during subsequent disintegration, only cell separation occurred. It can therefore be concluded that during cooking of fresh whole beans, progressive weakening of the middle lamella occurs and upon tissue disintegration, a transition from cell breakage to a combination of cell breakage and cell separation then a phase of cell separation only is observed. Similar behavior was observed for aged whole beans (Figure 3C) cooked in demineralised water except that the transitions were delayed, with for instance cell separation (only) being observed after cooking for $270 \mathrm{~min}$ compared to $60 \mathrm{~min}$ in the case of fresh whole beans. Between $60 \mathrm{~min}$ and $210 \mathrm{~min}$, the micrographs are not shown because the microstructure was similar to that shown for $60 \mathrm{~min}$. This demonstrates that the HTC defect retards the rate of pectin solubilisation from the middle lamella constituents, thereby delaying cell separation. In agreement with these results, scanning electron microscopy (SEM) on fresh and hardened black beans cooked for 120 min revealed advanced and minimal cell separation, respectively 
(Hincks et al., 1987). Moreover, Aguilera and Steinsapir (1985) also found cells of similarly treated fresh and hardened beans to show cell separation and cell breakage, respectively and attributed the latter observation to failure of the middle lamella to separate due to toughness.

For fresh and aged whole beans soaked and cooked in $0.1 \mathrm{M} \mathrm{NaHCO}_{3}$ solution (results not shown), similar trends as discussed above for whole beans cooked in demineralised water were observed. However, the transitions occurred much earlier. For instance, while cell separation (only) was attained after $60 \mathrm{~min}$ for fresh whole beans cooked in demineralised water (Figure $3 \mathrm{~A}$ ), for those cooked in $0.1 \mathrm{M} \mathrm{NaHCO}_{3}$ solution this transition was clear after $30 \mathrm{~min}$. This translates to faster solubilisation of pectin in the middle lamella, resulting in faster cooking. The cell disruption transitions observed and discussed above for all bean materials irrespective of the cooking medium are in agreement with texture evolution results (section 3.1). From Figure 2, all profiles showed the highest hardness for the soaked/noncooked beans which were characterized by strong middle lamella regions as discussed above. Hardness decreased with increased cooking times, corresponding to the phases characterized first by a combination of cell separation and breakage then cell separation only. The development of HTC resulted in longer cooking times of beans (Figure 2) because of its corresponding delay in pectin solubilisation compared with fresh beans. The early transition to cell separation (only) phase which implies faster pectin solubilisation in the middle lamella observed when beans were cooked in $0.1 \mathrm{M} \mathrm{NaHCO}_{3}$ solution is in line with the texture evolution results for beans cooked in this medium as shown in Figure 2.

It has been long established that pulses in general have low glycemic indices. The texturemicrostructure (after disintegration) relations revealed in this study suggest that beans are processed to a texture (hardness) that yields separate intact cells upon mastication. Therefore, starch granules might be unavailable for digestion due to enclosure by cell walls as was found by Brummer et al. (2015) and Noah et al. (1998), leading to a low glycemic index. Considering the tissue failure transitions observed in the current study during cooking, the severity of a treatment in modifying microstructure will determine the ratio of free to enclosed starch. This information is crucial for product development, especially considering products for targeted populations such as diabetics among others.

Visualization of the samples under polarized light was intended to provide a qualitative evaluation of the extent of starch gelatinisation as shown in Figure 3 ( $B$ and $D$ for fresh and aged beans, respectively) for materials cooked in demineralised water. Irrespective of the cooking medium, clear Maltese crosses were observed for cotyledons of both fresh and aged whole beans at 0 min cooking time, confirming that the starch was raw or non-gelatinised. No 
sooner had cooking started than Maltese crosses disappeared (at cooking times corresponding to the first sampling moments) but interestingly, starch granules exhibited residual birefringence which was sustained unabated up to the longest cooking time explored in this study. According to Wang et al. (2015), starch gelatinisation is associated with loss of birefringence which is characteristic of native (semi-crystalline) starch. Therefore, in the current study, the residual birefringence suggests that there was some molecular order in both fresh and aged beans cooked in either media. Contrary to middle lamella thermal solubilisation (due to pectin solubilisation) which was clearly retarded by the HTC defect, no clear influence of HTC on loss of Maltese crosses was exhibited. From these results, the relation between texture decay and loss of molecular order during cooking could not be ascertained due to the persistent residual birefringence hence a quantitative analysis of starch gelatinisation was performed and the results are discussed in the following section.

\subsection{Insight into starch gelatinisation from thermal analysis}

\subsubsection{Thermal properties of bean materials subjected to disintegration with a mortar and pestle}

In order to better interpret the residual birefringence observed in the current study (section 3.2), quantitative analysis of starch gelatinisation was performed using DSC. For fresh and aged beans soaked ( 0 min cooking time) in either media, two overlapping peaks were obtained, hence thermograms for fresh beans soaked in demineralised water only are shown in Figure 4. Peaks with temperature minima ( $\left.T_{\text {peak }}\right)$ between $80-84^{\circ} \mathrm{C}$ were attributed to mainly starch gelatinisation and the second between $86-91^{\circ} \mathrm{C}$ to protein denaturation. The peak ascribed to protein denaturation was confirmed after a reduction in its size due to loss of albumin proteins through extraction (Figure 4). In similar studies using flour from $P$. vulgaris beans, protein denaturation occurred at higher temperatures than starch gelatinisation (Wright and Boulter, 1980; Sosulski et al., 1985). Investigation of formation of amylose-lipid complexes revealed an influence of lipids in the case of fresh beans cooked for 0 min (F0') (Figure 4) which had no cellular structure after disintegration. For F120' (thermogram not shown) which had intact cells after disintegration, there was no difference in thermal events before and after lipid extraction possibly because the amylose-lipid complexes were already formed during cooking of the beans (section 2.2.1). It is a challenge to comment on the influence of HTC on each thermal event, especially starch gelatinisation since the obtained thermograms are a result of three different but overlapping thermal events. Significantly different enthalpies of gelatinisation were found between flours of raw non-hardened and hardened beans and this was attributed to limited water availability in the 
latter, leading to higher energy requirements for gelatinisation (Garcia-Vela and Stanley, 1989).

Thermograms for fresh and aged samples cooked in either media for any period of time revealed two major distinct peaks as shown in Figure 5 for fresh beans cooked in demineralised water. The peak with a $T_{\text {peak }}$ spanning the range $59-64{ }^{\circ} \mathrm{C}$ can be ascribed to starch retrogradation whilst the one between $90^{\circ} \mathrm{C}$ and $101^{\circ} \mathrm{C}$ can be attributed to possibly amylose-lipid complexes. Retrogradation is the continuous reassociation of disaggregated starch polymers initiated by rapid recrystallization of amylose and later slow recrystallization of amylopectin upon cooling of gelatinised starch. Such restructuring results in a partially ordered structure that differs from the native structure (Wang et al., 2015). The transition temperatures for starch retrogradation were comparable for both fresh and aged whole beans cooked in either media and were not influenced by cooking time (Supplementary Table 1). Moreover, for all samples, enthalpy values associated with retrogradation were comparable but with no clear trends. This suggests that retrogradation was not influenced by the cooking time of bean materials. Along with the aforementioned major peaks, a very small peak with a $T_{\text {peak }}$ of around $82^{\circ} \mathrm{C}$ was observed for all samples regardless of the cooking medium and was attributed to residual enthalpy for complete starch gelatinisation/loss of order. This was insignificant $(<1 \%)$, indicating that starch was almost completely gelatinised (in both fresh and aged whole beans) after $30 \mathrm{~min}$ and $15 \mathrm{~min}$ of cooking in demineralised water and $0.1 \mathrm{M} \mathrm{NaHCO}_{3}$, respectively. It is possible that this was achieved at a much earlier stage during cooking (earlier than the first sampling moments explored in this study).

\subsubsection{Thermal properties of bean materials subjected to cryogenic milling}

Fresh and aged whole beans cooked to a texture that facilitated cell separation only upon tissue disintegration were cryomilled in order to embrittle the cell wall and destroy its restrictive nature (structural barrier) that could influence thermal behavior of beans during cooking. Figure 6 shows thermograms for F120' and aged whole beans cooked for 330 min (A300') which reveal that for both samples, no significant changes (statistical results shown in Supplementary Table 2) in retrogradation $T_{\text {peak }}$ and enthalpy were noted following release of starch granules due to disintegration of cell walls. In addition, the insignificant $(<1 \%)$ peak attributed to residual enthalpy for complete starch gelatinisation was observed as before (section 3.3.1). These results confirm that starch gelatinisation occurred early in the cooking process at times stated in the previous section and that the cell wall did not restrict hydration of starch for gelatinisation as was suggested by Berg et al. (2012) and Brummer et al. (2015). Rather, there was a volume limitation for uncoiling and subsequent pasting of the 
starch (granules) due to restriction by the cell walls. It is therefore not surprising that as long as the cell wall was a barrier for starch uncoiling, the extent of starch gelatinisation was similar for fresh and aged beans and so was the retrogradation. However, Aguilera and Steinsapir (1985) reported complete gelatinisation of starch in non-hardened beans but not in hardened beans as a result of hardened cell wall material restricting expansion of the starch granules in the latter. Some researchers relate hardening of the cell wall to pectates and lignin which are believed to hinder cell separation during cooking of HTC beans, consequently impairing hydration and leading to minimal starch gelatinisation (Hincks et al., 1987). Microscopic and calorimetric evidence provided by the current study showed that cell separation which contributes to softening of beans owing to pectin solubilisation occurred much later during cooking compared to starch gelatinisation. Therefore, starch gelatinisation is not the rate-limiting mechanism that governs texture decay in beans but most possibly pectin solubilisation. Concerning residual birefringence, Varriano-Marston and Omana (1979) also observed it in black beans and attributed it to hindered swelling of starch granules owing to inherent granule characteristics, influence of other cellular structures or a combination of both. However, from our results, the most plausible explanation for this phenomenon is residual molecular order upon cooking and/or formed during retrogradation.

\section{Extensive studies on starch gelatinisation over the years yielded an exhaustive list of the} many stages involved including granular swelling, loss of birefringence, melting of crystallites, unwinding of double helices, solubilisation and paste formation (Ratnayake et al., 2009; Wang and Copeland, 2013). However, it is still unclear as to which stage the enthalpy of gelatinisation corresponds to. From results of the current study, it can be concluded that the cell wall did not restrict the process on which the enthalpy of starch gelatinisation is premised but the unwinding of double helices and subsequent pasting. A further confirmation for this was obtained after F0' and A0' samples (with no cellular structure) showed complete gelatinisation of starch (results not shown). Therefore, it can be hypothesised that the enthalpy of gelatinisation is associated with the simultaneous swelling and initial disruption of the native molecular order of starch granules before pasting.

\section{Conclusions}

This study demonstrated that during storage of beans under adverse conditions of temperature and relative humidity, cotyledons play a major role in the development of HTC, with seed coats having a minor contribution. This was evidenced by the texture evolution of beans during the cooking process being greatly influenced by the cotyledon, with only limited influence of the seed coat. Soaking and cooking of beans in a solution of high $\mathrm{pH}$ (containing 
monovalent cations) instead of demineralised water promoted faster cooking. Upon tissue disintegration, a link was established between evolution of tissue failure mechanisms and tissue softening, indicating that thermal processing-induced texture decay was mainly attributed to weakening of the middle lamella due to pectin solubilisation and, cell wall polysaccharide solubilisation. Starch gelatinisation is not the rate-limiting step in bean tissue softening but the cell wall restricted uncoiling and gelling of gelatinised starch. These results strongly suggest that the mechanism that governs texture decay during cooking of beans can be related to changes in the cell wall and middle lamella. Therefore, for a better mechanistic understanding of HTC development and cooking behavior of common beans, research focus should be on modification and/or solubilisation of polymers in the cell wall and middle lamella of cotyledon cells during storage and/or cooking.

\section{Acknowledgements}

Chigwedere C.M. is a Ph.D. fellow funded by the Interfaculty Council for Development Cooperation (IRO). Kyomugasho $\mathrm{C}$. is a postdoctoral researcher funded by the Onderzoeksfonds KU Leuven post-doctoral fellowship (PDM).

\section{References}

Aguilera, J. M. and Steinsapir, A. (1985). Dry processes to retard quality losses of beans (Phaseolus vulgaris) during storage. Canadian Institute of Food Science and Technology Journal, 18(1), 72-78.

Berg, T., Singh, J., Hardacre, A. and Boland, M. J. (2012). The role of cotyledon cell structure during in vitro digestion of starch in navy beans. Carbohydrate Polymers, 87(2), 1678-1688.

Berrios, J. D. J., Swanson, B. G. and Cheong, W. A. (1999). Physico-chemical characterization of stored black beans (Phaseolus vulgaris L.). Food Research International, 32(10), 669-676.

Binner, S., Jardine, W. G., Renard, C. M. C. G. and Jarvis, M. C. (2000). Cell wall modifications during cooking of potatoes and sweet potatoes. Journal of the Science of Food and Agriculture, 80(2), 216-218.

Brummer, Y., Kaviani, M. and Tosh, S. M. (2015). Structural and functional characteristics of dietary fibre in beans, lentils, peas and chickpeas. Food Research International, 67, 117125.

Cuvelier, K., Storsley, J., Mollard, R., Thandapilly, S. J. and Ames, N. (2017). A review of the impact of whole pulses on glycemic response. Cereal Foods World, 62(2), 53-58.

del Valle, J. M. and Stanley, D. W. (1995). Reversible and irreversible components of bean hardening. Food Research International, 28(5), 455-463. 
dos Santos Siqueira, B., Vianello, R. P., Fernandes, K. F. and Bassinello, P. Z. (2013). Hardness of carioca beans (Phaseolus vulgaris L.) as affected by cooking methods. LWT - Food Science and Technology, 54(1), 13-17.

Downie, A. J., Georget, D. M. R., Smith, A. C. and Waldron, K. W. (1997). Application of dynamic mechanical thermal analysis to the investigation of hard-to-cook defect in legumes. LWT - Food Science and Technology, 30(3), 312-319.

El-Tabey Shehata, A. M. (1992). Hard-to-cook phenomenon in legumes. Food Reviews International, 8(2), 191-221.

Garcia-Vela, L. A. and Stanley, D. W. (1989). Protein denaturation and starch gelatinization in hard-to-cook beans. Journal of Food Science, 54(5), 284-1286.

Hincks, M. J., McCannel, A. and Stanley, D. W. (1987). Hard-to-cook defect in black beans. Soaking and cooking processes. Journal of Agricultural and Food Chemistry, 35(4), 576583.

Hincks, M. J. and Stanley, D. W. (1986). Multiple mechanisms of bean hardening. Journal of Food Technology, 21(6), 731-750.

Hincks, M. J. and Stanley, D. W. (1987). Lignification: evidence for a role in hard-to-cook beans. Journal Food Biochemistry, 11(1), 41-58.

Hohlberg, A. I. and Stanley, D. W. (1987). Hard-to-cook defect in black beans. Protein and starch considerations. Journal of Agricultural and Food Chemistry, 35(4), 571-576.

Hoover, R., Hughes, T., Chung, H. J. and Liu, Q. (2010). Composition, molecular structure, properties, and modification of pulse starches: A review. Food Research International, 43(2), 399-413.

Jackson, M. G. and Varriano-Marston, E. (1981). Hard-to-cook phenomenon in beans: effects of accelerated storage on water absorption and cooking time. Journal of Food Science, 46(3), 799-803.

Kikuchi, K., Koizumi, M., Ishida, N. and Kano, H. (2006). Water uptake by dry beans observed by micro-magnetic resonance imaging. Annals of Botany, 98(3), 545-553.

Kinyanjui, P. K., Njoroge, D. M., Makokha, A. O., Christiaens, S., Ndaka, D. S. and Hendrickx, M. (2015). Hydration properties and texture fingerprints of easy- and hard-tocook bean varieties. Food Science and Nutrition, 3(1), 39-47.

Liu, K., Mcwatters, K. H. and Phillips, R. D. (1992). Protein insolubilization and thermal destabilization during storage as related to hard-to-cook defect in cowpeas. Journal of Agricultural and Food Chemistry, 40(12), 2403-2407.

Machado, C. M., Ferruzzi, M. G. and Nielsen, S. S. (2008). Impact of the hard-to-cook phenomenon on phenolic antioxidants in dry beans (Phaseolus vulgaris). Journal of Agricultural and Food Chemistry, 56(9), 3102-3110. 
Martin-Cabrejas, M. A., Esteban, R. M., Perez, P., Maina, G. and Waldron, K. W. (1997). Changes in physicochemical properties of dry beans (Phaseolus vulgaris L.) during longterm storage. Journal of Agricultural and Food Chemistry, 45(8), 3223-3227.

Menoli, A. V. and Beleia, A. (2007). Starch and pectin solubilization and texture modification during pre-cooking and cooking of cassava root (Manihot esculenta Crantz). LWT - Food Science and Technology, 40(4), 744-747.

Mikac, U., Sepe, A. and Serša, I. (2015). MR microscopy for noninvasive detection of water distribution during soaking and cooking in the common bean. Magnetic resonance Imaging, 33(3), 336-345.

Njoroge, D. M., Kinyanjui, P. K., Chigwedere, C. M., Christiaens, S., Makokha, A. O., Sila, D. N. and Hendrickx, M. E. (2016). Mechanistic insight into common bean pectic polysaccharide changes during storage, soaking and thermal treatment in relation to the hard-to-cook defect. Food Research International, 81, 39-49.

Noah, L., Guillon, F., Bouchet, B., Buléon, A., Molis, C., Gratas, M. and Champ, M. (1998). Digestion of carbohydrate from white beans (Phaseolus vulgaris $L$.) in healthy humans. The Journal of nutrition, 128(6), 977-985.

Paredes-López, O., Carabez-Trejo, A., Palma-Tirado, L. and Reyes-Moreno, C. (1991). Influence of hardening procedure and soaking solution on cooking quality of common beans. Plant Foods for Human Nutrition, 41(2), 155-164.

Piergiovanni, A. R. (2011). Kinetic of water adsorption in common bean: considerations on the suitability of Peleg's model for describing bean hydration. Journal of Food Processing and Preservation, 35(4), 447-452.

Pirhayati, M., Soltanizadeh, N. and Kadivar, M. (2011). Chemical and microstructural evaluation of "hard-to-cook" phenomenon in legumes (pinto bean and small-type lentil). International Journal of Food Science and Technology, 46(9), 1884-1890.

Ratnayake, W. S., Otani, C. and Jackson, D. S. (2009). DSC enthalpic transitions during starch gelatinisation in excess water, dilute sodium chloride and dilute sucrose solutions. Journal of the Science of Food and Agriculture, 89(12), 2156-2164.

Reyes-Moreno, C., Okamura-Esparza, J., Armienta-Rodelo, E., Gomez-Garza, R. M. and Milan-Carrillo, J. (2000). Hard-to-cook phenomenon in chickpeas (Cicer arietinum L.): effect of accelerated storage on quality. Plant Foods for Human Nutrition, 55(3), 229-241.

Schoeninger, V., Coelho, S. R. M., Christ, D. and Sampaio, S. C. (2014). Processing parameter optimization for obtaining dry beans with reduced cooking time. LWT - Food Science and Technology, 56(1), 49-57.

Sila, D. N., Smout, C., Vu, S. T., Van Loey, A. and Hendrickx, M. (2005). Influence of pretreatment conditions on the texture and cell wall components of carrots during thermal 
processing. Journal of Food Science, 70(2), E85-E91.

Sosulski, B. F. W., Hoover, R. and Tyler, R. T. (1985). Differential scanning calorimetry of airclassified starch and protein fractions from eight legume species. Starch-Stārke, 26(8), 257-262.

Stanley, D. W. (1992). A possible role for condensed tannins in bean hardening. Food Research International, 25(3), 187-192.

Stolle-Smits, T., Beekhuizen, J. G., Recourt, K., Voragen, A. G. J. and Van Dijk, C. (1997). Changes in pectic and hemicellulosic polymers of green beans (Phaseolus vulgaris L.) during industrial processing. Analysis, 45(12), 4790-4799.

Swanson, B. G., Hughes, J. S. and Rasmussen, H. P. (1985). Seed microstructure: review of water imbibition in legumes. Food Structure, 4(1), 115-124.

Varriano-Marston, E. and Omana, E. (1979). Effects of sodium salt solutions on the chemical composition and morphology of black beans (Phaseolus vulgaris). Journal of Food Science, 44(2), 531-536.

Waldron, K. W., Parker, M. L. and Smith, A. C. (2003). Plant cell walls and food quality. Comprehensive Reviews in Food Science and Food Safety, 2(4), 128-146.

Wang, S., Li, C., Copeland, L., Niu, Q. and Wang, S. (2015). Starch retrogradation: A comprehensive review. Comprehensive Reviews in Food Science and Food Safety, 14(5), 568-585.

Wang, S. and Copeland, L. (2013). Molecular disassembly of starch granules during gelatinization and its effect on starch digestibility: A review. Food and Function, 4(11), 1564-1580.

Wright, D. J. and Boulter, D. (1980). Differential scanning calorimetric study of meals and constituents of some food. Journal of the Science of Food and Agriculture, 31(12), 12311241.

Wu, S., Feng, S. and Kojima, M. (2015). Effects of different storage on qualities of adzuki and red kidney beans. Journal of Food Research, 4(3), 103-117.

Zhang, L. and McCarthy, M. J. (2013). NMR study of hydration of navy bean during cooking. LWT - Food Science and Technology, 53(2), 402-408. 
628 Tables and Figures

629 Table

630 Table 1. Parameter estimates \pm standard errors for softening of fresh/aged whole beans and

631 cotyledons cooked in demineralised water and $0.1 \mathrm{M} \mathrm{NaHCO}_{3}$ solution. Delta-time $(\Delta \mathrm{t})$ is

632 time for which hardness at any time less than or equal to $\Delta t$ is equal to the initial hardness, $k$

633 is the rate constant for softening as determined from $\Delta \mathrm{t}$ min to the longest cooking time

634 explored for the material and RMSE is root mean square error. The k-values having different

635 superscript letters are significantly different.

\begin{tabular}{lcccc}
\hline Bean material and treatment & $\Delta \mathbf{t}(\mathbf{m i n})$ & $\mathbf{k}\left(\mathbf{x ~ 1 0 ^ { 3 } )} \mathbf{m i n}^{-1}\right.$ & $\begin{array}{l}\mathbf{R}^{\mathbf{2}} \\
\text { adjusted }\end{array}$ & $\mathbf{R M S E}\left(\mathbf{x ~ \mathbf { 1 0 } ^ { 2 } )}\right.$ \\
\hline Materials cooked in demineralised $\mathrm{H}_{2} \mathrm{O}$ & & & & \\
Fresh whole beans & & & & \\
Aged whole beans & $6.80 \pm 7.05$ & $11.2 \pm 1.25^{\mathrm{e}}$ & 0.99 & 5.00 \\
Fresh cotyledons & $16.3 \pm 5.78$ & $4.12 \pm 0.19^{\dagger}$ & 0.99 & 3.00 \\
Aged cotyledons & $18.4 \pm 1.55$ & $17.0 \pm 0.67^{\mathrm{d}}$ & 0.99 & 2.00 \\
Materials cooked in 0.1 $\mathrm{M} \mathrm{NaHCO}_{3}$ & $53.1 \pm 4.07$ & $6.19 \pm 0.33^{\dagger}$ & 0.99 & 2.80 \\
Fresh whole beans & & & & \\
Aged whole beans & $14.9 \pm 0.08$ & $68.2 \pm 0.80^{\mathrm{b}}$ & 0.99 & 0.50 \\
Fresh cotyledons & $17.0 \pm 1.93$ & $33.8 \pm 2.58^{\mathrm{c}}$ & 0.99 & 2.80 \\
Aged cotyledons & $9.14 \pm 0.26$ & $89.3 \pm 4.02^{\mathrm{a}}$ & 0.99 & 2.00 \\
\hline
\end{tabular}

636

637

638

639

640

641

642

643

644

645

646

647

648

649

650

651 
652

653

654

655

656

657

658

659

660

661

662

663

664

665

666

667

668

669

670

671

672

673

674
Figures

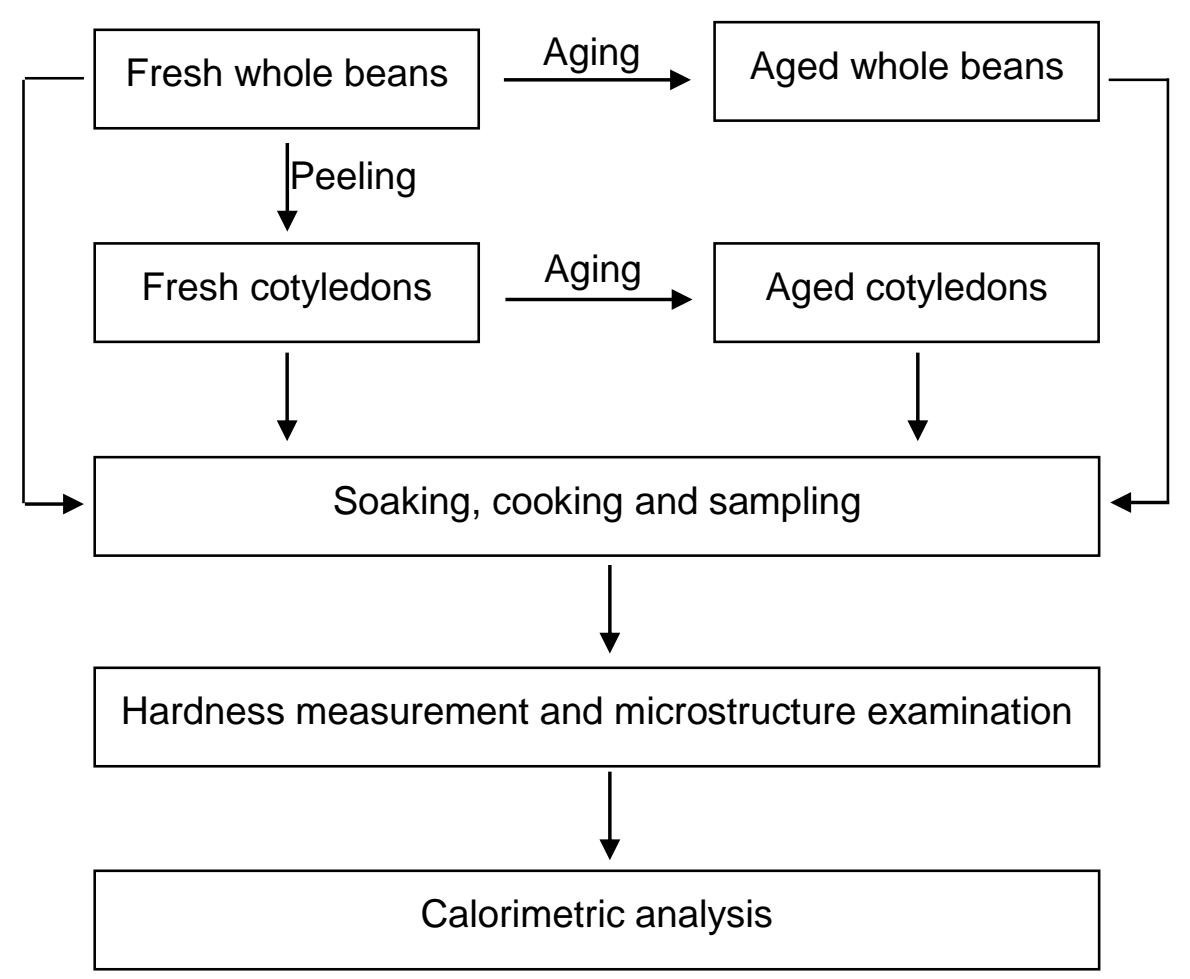

Fig. 1 Schematic illustration of the experimental approach for this study 


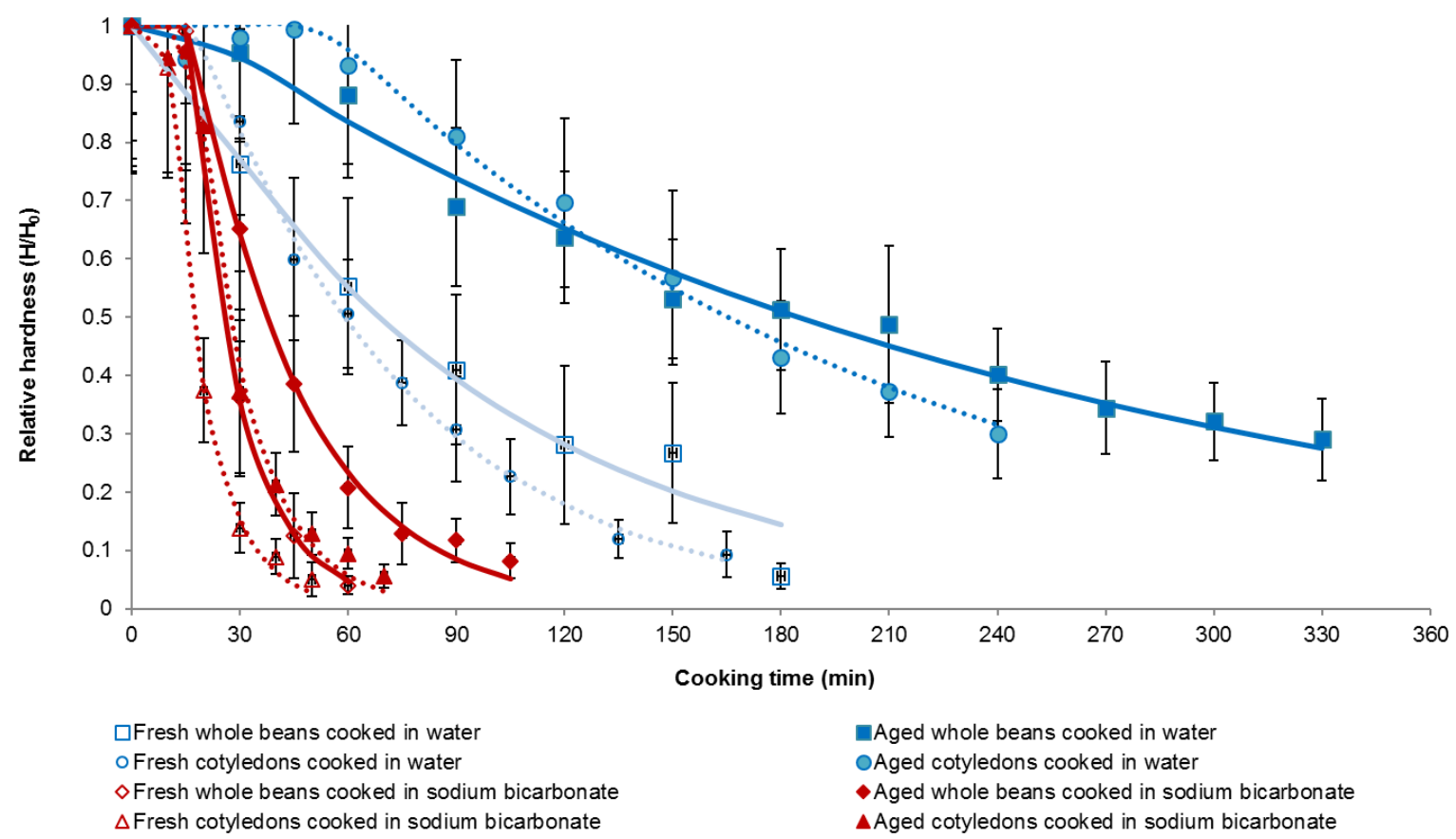

Figure 2. Cooking profiles of fresh and aged whole beans and cotyledons cooked as such in demineralised water (blue) and $0.1 \mathrm{M} \mathrm{NaHCO}_{3}$ (maroon). Markers represent mean values of 20 hardness measurements from 20 cotyledons (whole beans were peeled before hardness measurements) expressed as a ratio of the initial hardness $\left(\mathrm{H} / \mathrm{H}_{0}\right)$. Solid and dashed lines denote modeled data for cotyledons from whole beans and cotyledons conditioned as such,

681 respectively.

682

683

684

685

686

687

688

689

690

691

692

693

694

695 


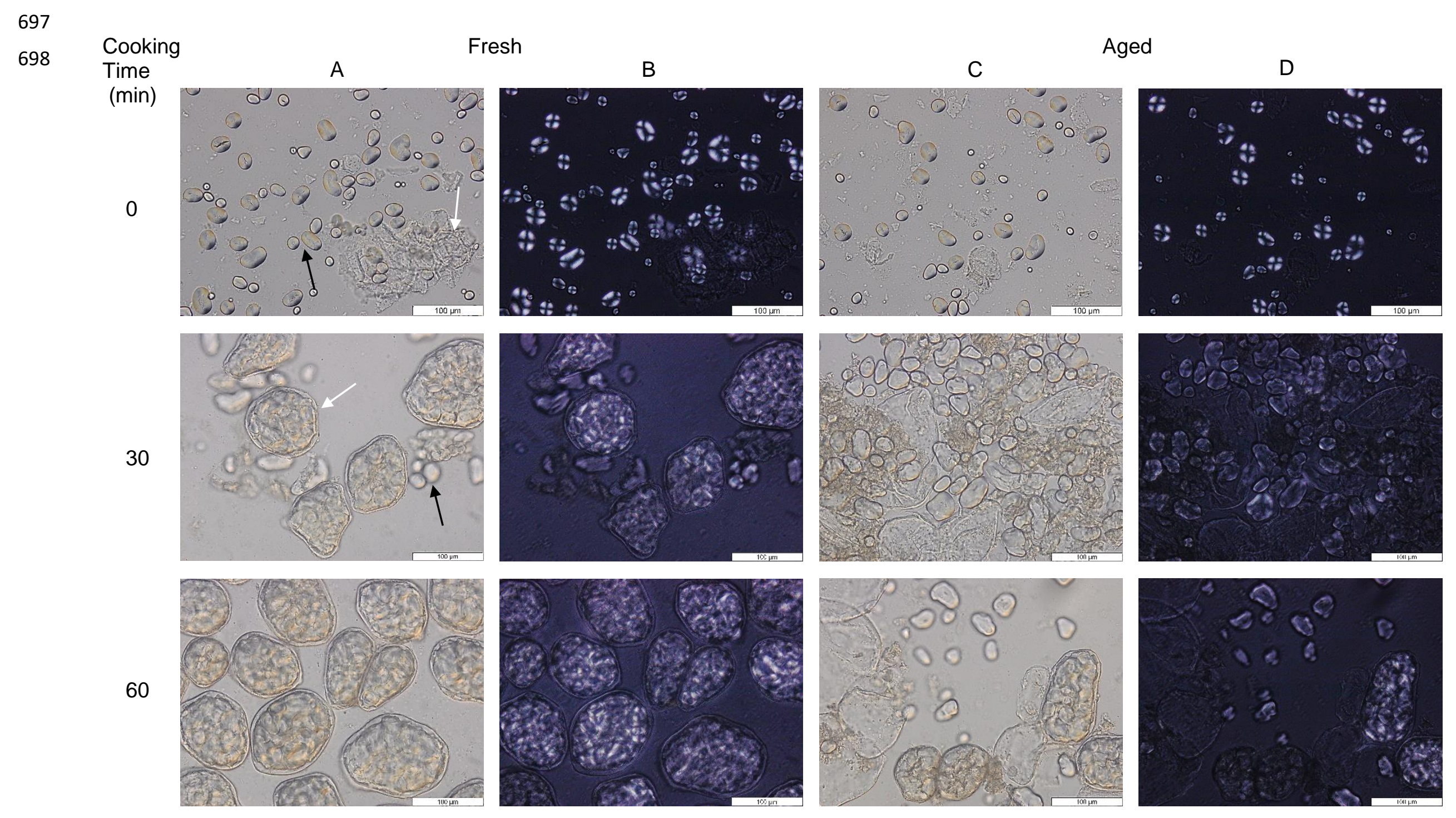


210
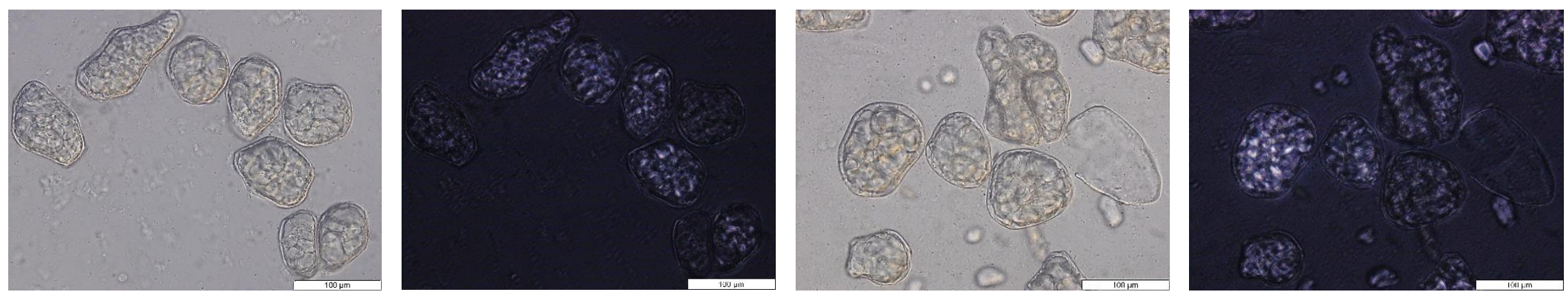

240
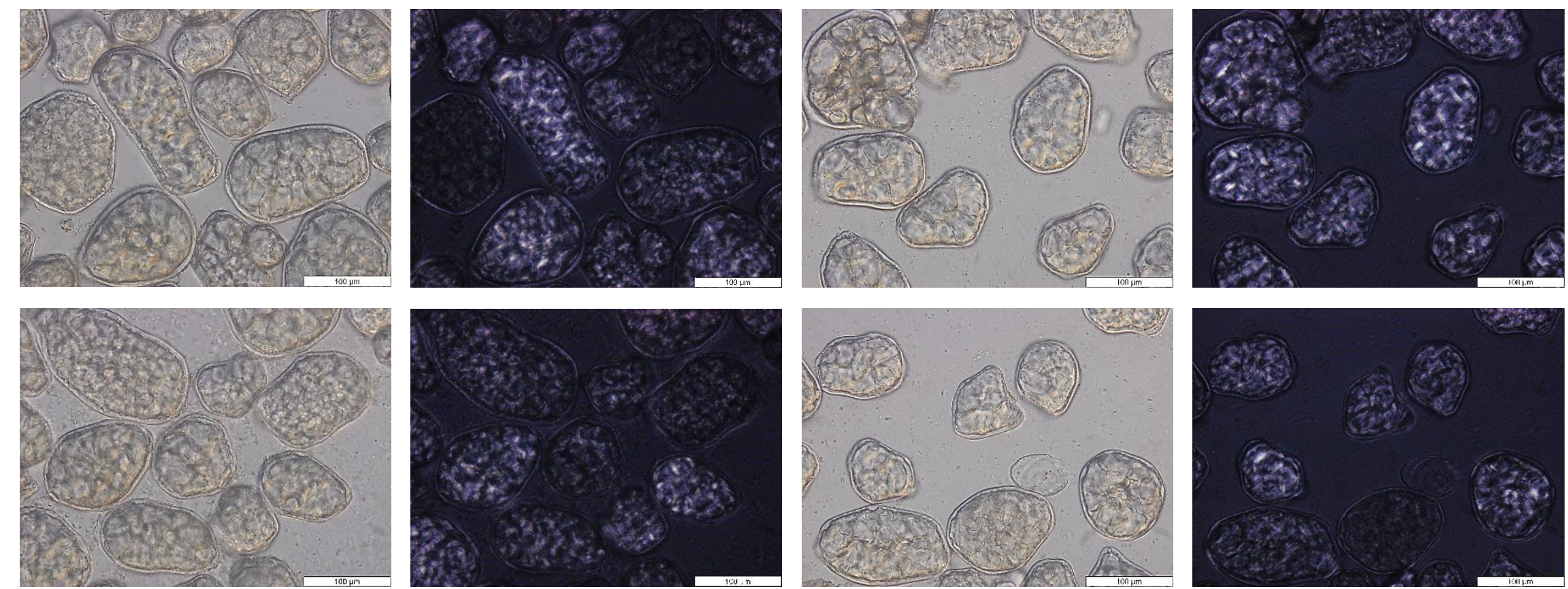
704 Fig. 3 Micrographs of cotyledons from fresh ( $A$ and $B$ ) and aged ( $C$ and $D)$ whole beans cooked in demineralised water for different cooking 705 times and disintegrated with mortar and pestle as viewed under differential interference contrast $(A$ and $C)$ and polarized light (B and $D)$ modes. 706 The black and white arrows on the micrograph of cotyledons from fresh beans cooked for 0 min (A) show free starch granules and cell wall 707 material, respectively, whilst for the same bean material cooked for 30 min they show free starch granules and intact cells, respectively. Scale $708 \quad$ bar $=100 \mu \mathrm{m}$. 


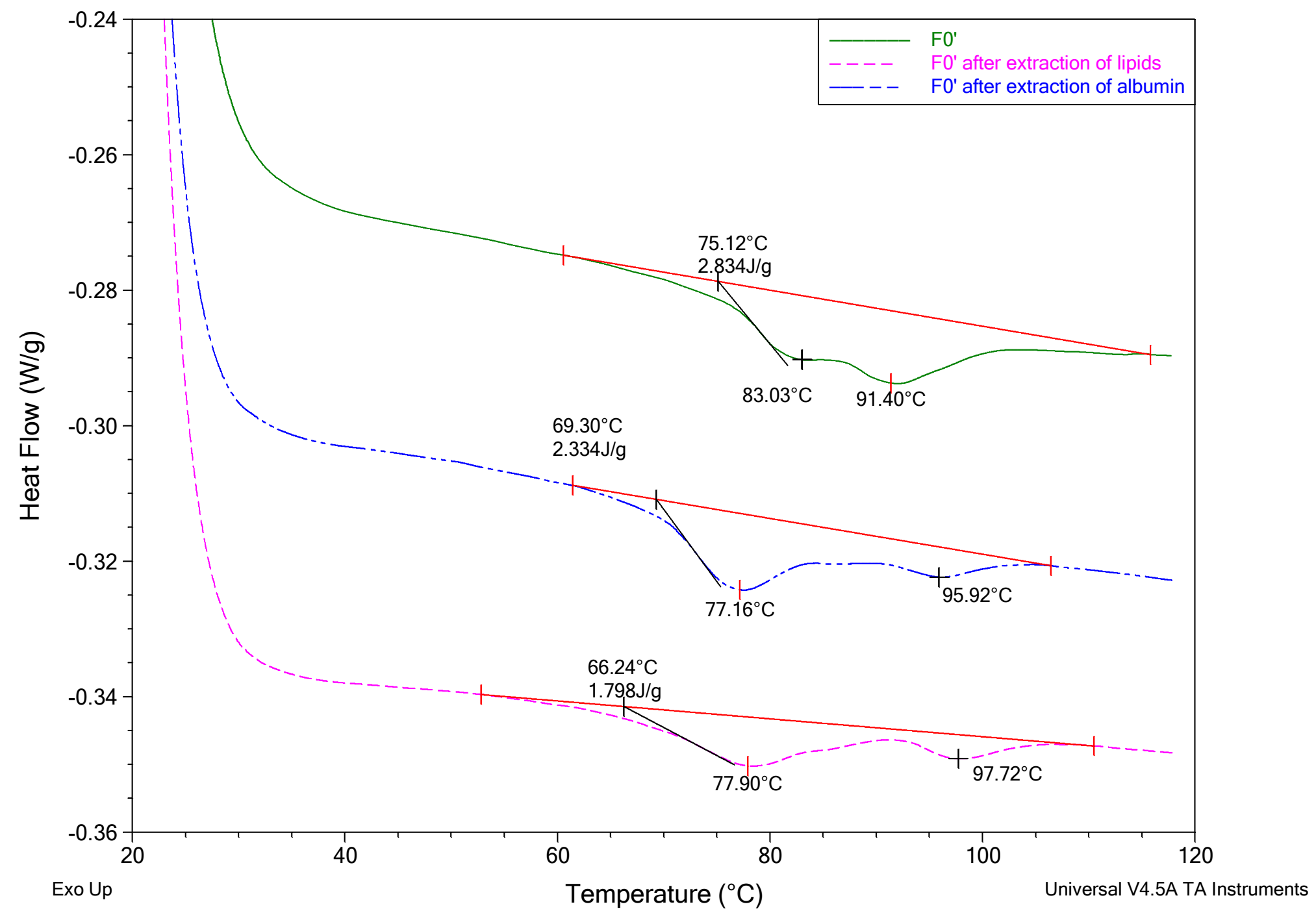

Figure 4. The effect of extraction of albumin and lipids on the thermal events of cotyledon powders obtained from fresh whole beans soaked in demineralised water (FO') 


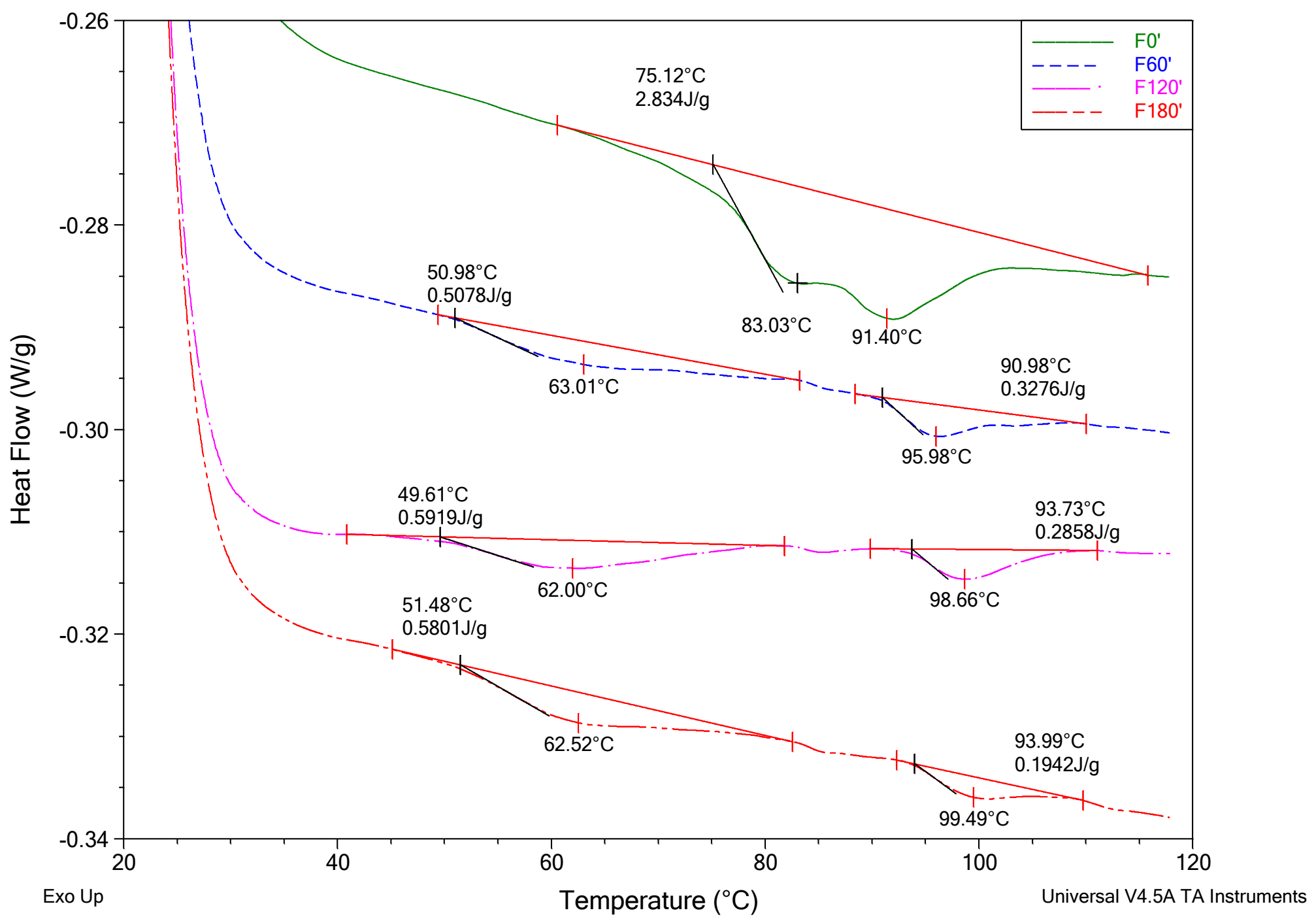

771 Figure 5. Thermal events of cotyledon powders obtained from fresh beans cooked in demineralised water for different times 


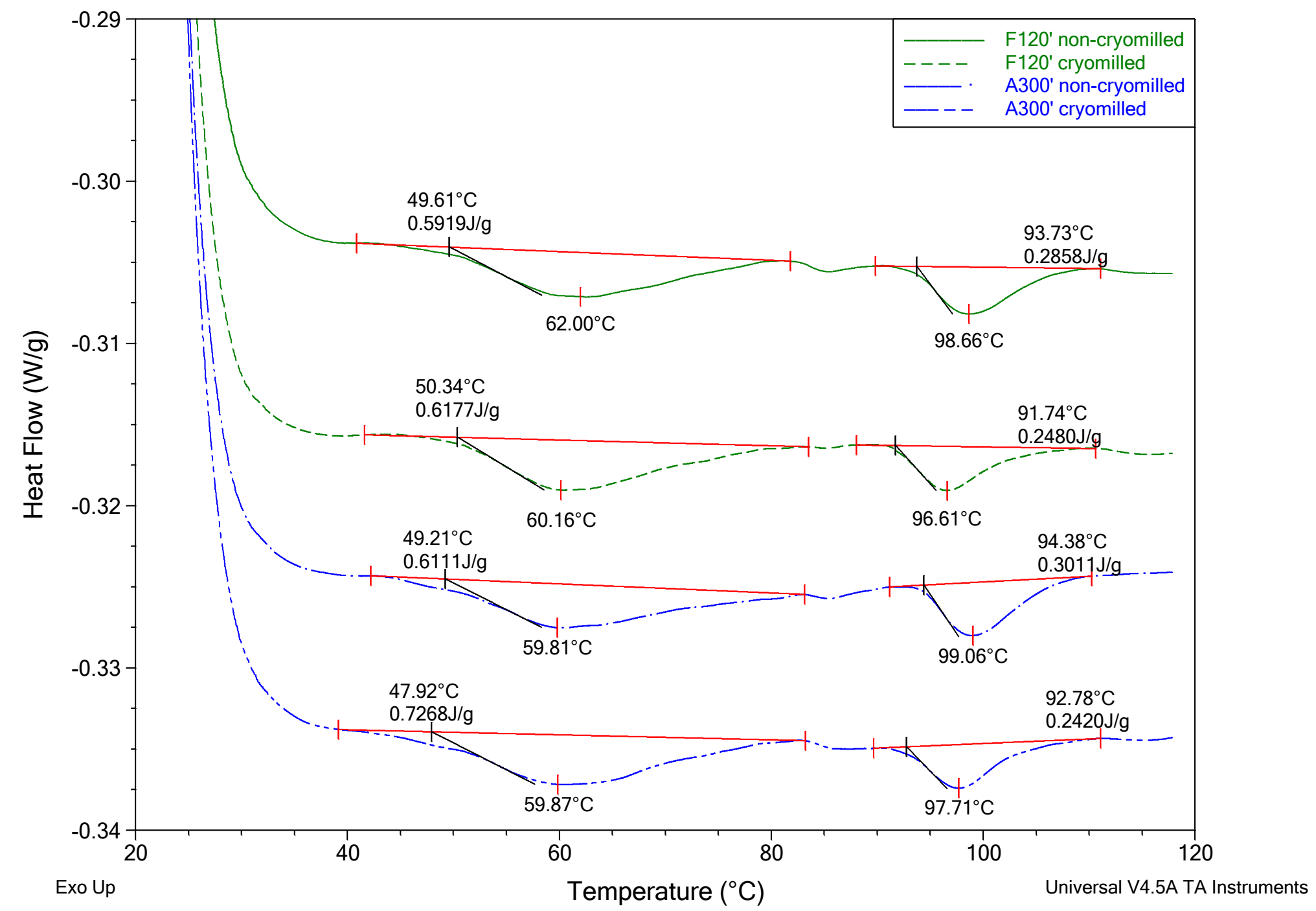

Figure 6 . The effect of cell wall removal by cryomilling on thermal events of cotyledon powders obtained from fresh whole beans cooked for $120 \mathrm{~min}$ (F120') and aged whole beans cooked for $330 \mathrm{~min}$ (A330') in demineralised water. 


\section{Supplementary tables}

Supplementary Table 1. Transition temperatures and enthalpy of thermal events of lyophilized cotyledon powder obtained from whole beans cooked in demineralised water and $0.1 \mathrm{M} \mathrm{NaHCO}_{3}$ for different times. Values are averages of analyses done in duplicate \pm standard deviations. $A$ and $F$ represent aged and fresh, respectively, while associated numbers represent cooking times. Values having different superscript letters are significantly different with lower and upper case letters being used for fresh and aged beans, respectively.

Cooked in demineralised water

Cooked in $0.1 \mathrm{M} \mathrm{NaHCO}_{3}$

\begin{tabular}{|c|c|c|c|c|c|c|c|c|c|}
\hline \multicolumn{5}{|c|}{ Cooked in demineralised water } & \multicolumn{5}{|c|}{ Cooked in $0.1 \mathrm{M} \mathrm{NaHCO}_{3}$} \\
\hline \multirow{2}{*}{$\begin{array}{l}\text { Sample } \\
\text { Code }\end{array}$} & \multicolumn{2}{|c|}{ Starch retrogradation } & \multicolumn{2}{|c|}{ Amylose-lipid complex } & \multirow{2}{*}{$\begin{array}{l}\text { Sample } \\
\text { Code }\end{array}$} & \multicolumn{2}{|c|}{ Starch retrogradation } & \multicolumn{2}{|c|}{ Amylose-lipid complex } \\
\hline & Enthalpy $(\mathrm{J} / \mathrm{g})$ & $\mathrm{T}_{\text {peak }}\left({ }^{\circ} \mathrm{C}\right)$ & Enthalpy $(\mathrm{J} / \mathrm{g})$ & $\mathrm{T}_{\text {peak }}\left({ }^{\circ} \mathrm{C}\right)$ & & Enthalpy $(\mathrm{J} / \mathrm{g})$ & $\mathrm{T}_{\text {peak }}\left({ }^{\circ} \mathrm{C}\right)$ & Enthalpy $(\mathrm{J} / \mathrm{g})$ & $\mathrm{T}_{\text {peak }}\left({ }^{\circ} \mathrm{C}\right)$ \\
\hline F30' & $0.39 \pm 0.03^{d}$ & $62.6 \pm 0.3^{a}$ & $0.43 \pm 0.04^{a}$ & $93.8 \pm 0.2^{\mathrm{e}}$ & F15' & $0.39 \pm 0.04^{\mathrm{bc}}$ & $61.3 \pm 0.6^{b}$ & $0.95 \pm 0.06^{a}$ & $91.2 \pm 0.5^{c}$ \\
\hline F60' & $0.49 \pm 0.02^{c}$ & $61.8 \pm 1.7^{a}$ & $0.34 \pm 0.02^{b}$ & $96.0 \pm 0.1^{d}$ & F30' & $0.44 \pm 0.05^{b}$ & $62.9 \pm 0.8^{a}$ & $0.67 \pm 0.01^{b}$ & $93.4 \pm 0.3^{b}$ \\
\hline F90' & $0.52 \pm 0.01^{b c}$ & $63.0 \pm 0.2^{\mathrm{a}}$ & $0.18 \pm 0.03^{c}$ & $97.6 \pm 0.1^{c}$ & $\mathrm{~F} 45^{\prime}$ & $0.31 \pm 0.04^{c}$ & $63.3 \pm 0.1^{\mathrm{a}}$ & $0.58 \pm 0.02^{b}$ & $95.3 \pm 0.2^{\mathrm{a}}$ \\
\hline F120' & $0.59 \pm 0.00^{\mathrm{a}}$ & $61.7 \pm 0.4^{a}$ & $0.29 \pm 0.00^{b}$ & $98.7 \pm 0.1^{\mathrm{bc}}$ & F60' & $0.58 \pm 0.01^{\mathrm{a}}$ & $59.7 \pm 0.0^{c}$ & $0.39 \pm 0.01^{c}$ & $96.4 \pm 0.1^{\mathrm{a}}$ \\
\hline $\mathrm{F} 150^{\prime}$ & $0.54 \pm 0.05^{\mathrm{abc}}$ & $63.0 \pm 0.2^{\mathrm{a}}$ & $0.18 \pm 0.03^{c}$ & $99.3 \pm 0.2^{\mathrm{ab}}$ & $\mathrm{F} 75^{\prime}$ & $0.59 \pm 0.04^{a}$ & $59.8 \pm 0.0^{c}$ & $0.44 \pm 0.09^{c}$ & $96.4 \pm 0.8^{a}$ \\
\hline F180' & $0.59 \pm 0.01^{\mathrm{ab}}$ & $63.3 \pm 1.0^{\mathrm{a}}$ & $0.18 \pm 0.02^{c}$ & $100.4 \pm 1.2^{\mathrm{a}}$ & & & & & \\
\hline A30' & $0.47 \pm 0.05^{\mathrm{BC}}$ & $59.3 \pm 0.9^{B}$ & $0.70 \pm 0.08^{A}$ & $92.9 \pm 0.2^{F}$ & $A 15^{\prime}$ & $0.26 \pm 0.07^{\circ}$ & $59.8 \pm 0.1^{\mathrm{A}}$ & $0.98 \pm 0.05^{A}$ & $90.7 \pm 0.9^{\mathrm{E}}$ \\
\hline A60' & $0.33 \pm 0.00^{c}$ & $60.1 \pm 0.2^{\mathrm{AB}}$ & $0.56 \pm 0.14^{\mathrm{A}}$ & $94.3 \pm 0.0^{\mathrm{E}}$ & A30' & $0.35 \pm 0.07^{\mathrm{BC}}$ & $60.7 \pm 1.4^{\mathrm{A}}$ & $0.64 \pm 0.01^{B}$ & $93.3 \pm 0.5^{\mathrm{D}}$ \\
\hline A90' & $0.59 \pm 0.00^{\mathrm{AB}}$ & $60.8 \pm 0.1^{\mathrm{AB}}$ & $0.32 \pm 0.02^{\mathrm{B}}$ & $95.3 \pm 0.0^{\mathrm{D}}$ & A45' & $0.47 \pm 0.00^{\mathrm{AB}}$ & $59.5 \pm 0.4^{\mathrm{A}}$ & $0.67 \pm 0.03^{\mathrm{B}}$ & $99.0 \pm 0.2^{A}$ \\
\hline A120' & $0.46 \pm 0.16^{\mathrm{BC}}$ & $60.7 \pm 0.7^{\mathrm{AB}}$ & $0.40 \pm 0.05^{\mathrm{B}}$ & $96.2 \pm 0.2^{C}$ & A60' & $0.51 \pm 0.10^{A}$ & $60.3 \pm 0.2^{A}$ & $0.58 \pm 0.11^{\mathrm{BC}}$ & $94.4 \pm 0.3^{C}$ \\
\hline A150' & $0.54 \pm 0.06^{\mathrm{AB}}$ & $60.4 \pm 1.6^{\mathrm{AB}}$ & $0.29 \pm 0.01^{B}$ & $97.0 \pm 0.1^{\mathrm{B}}$ & $A 75^{\prime}$ & $0.48 \pm 0.11^{\mathrm{AB}}$ & $60.0 \pm 0.9^{A}$ & $0.40 \pm 0.08^{\mathrm{D}}$ & $96.3 \pm 0.7^{\mathrm{B}}$ \\
\hline A180' & $0.65 \pm 0.01^{A}$ & $61.1 \pm 0.5^{A}$ & $0.32 \pm 0.04^{\mathrm{B}}$ & $97.2 \pm 0.2^{\mathrm{B}}$ & A90' & $0.60 \pm 0.03^{A}$ & $59.7 \pm 0.4^{A}$ & $0.46 \pm 0.02^{\mathrm{CD}}$ & $99.6 \pm 0.1^{A}$ \\
\hline A270' & $0.67 \pm 0.01^{A}$ & $60.3 \pm 0.1^{\mathrm{AB}}$ & $0.26 \pm 0.03^{\mathrm{B}}$ & $98.8 \pm 0.0^{A}$ & A105' & $0.52 \pm 0.03^{A}$ & $59.2 \pm 0.4^{\mathrm{A}}$ & $0.51 \pm 0.01^{C D}$ & $99.5 \pm 0.1^{A}$ \\
\hline А330' & $0.56 \pm 0.00^{\mathrm{AB}}$ & $59.8 \pm 0.2^{\mathrm{AB}}$ & $0.30 \pm 0.02^{\mathrm{B}}$ & $98.6 \pm 0.0^{A}$ & & & & & \\
\hline
\end{tabular}


Supplementary Table 2. Transition temperatures and enthalpy of starch retrogradation of cryomilled and non-cryomilled cotyledon powders obtained from fresh whole beans cooked in demineralised water for 120 min (F120') and aged beans cooked in demineralised water for 330 min (A330'). Values are averages of analyses done in duplicate \pm standard deviations. Values having different superscript letters are significantly different with lower and upper case letters being used for fresh and aged beans, respectively.

\begin{tabular}{llll}
\hline & Sample & \multicolumn{2}{c}{ Starch retrogradation } \\
& Code & Enthalpy $(\mathrm{J} / \mathrm{g})$ & $\mathrm{T}_{\text {peak }}\left({ }^{\circ} \mathrm{C}\right)$ \\
\hline Noncryomilled & $\mathrm{F} 120^{\prime}$ & $0.59 \pm 0.00^{\mathrm{a}}$ & $61.7 \pm 0.4^{\mathrm{a}}$ \\
Cryomilled & $\mathrm{F} 120^{\prime}$ & $0.64 \pm 0.03^{\mathrm{a}}$ & $60.6 \pm 0.7^{\mathrm{a}}$ \\
\hline Noncryomilled & $\mathrm{A}^{2} 00^{\prime}$ & $0.61 \pm 0.01^{\mathrm{A}}$ & $59.7 \pm 0.2^{\mathrm{A}}$ \\
Cryomilled & $\mathrm{A} 300^{\prime}$ & $0.69 \pm 0.05^{\mathrm{A}}$ & $59.9 \pm 0.1^{\mathrm{A}}$ \\
\hline
\end{tabular}

